\title{
Insecurities and Human Rights Issues of People Affected by Development-Induced Displacement
}

\author{
Pinki Kumari*
}

\begin{abstract}
Development and displacement seem to be directly related to each other. As India is a densely populated country, any development project leads to the displacement of lakhs of people. Displacement is not just the physical relocation of displaced people but is also associated with social and economic consequences that disrupt the lives of people. The insecurities resulting from the same are manifold. They include human insecurity, social insecurity, economic insecurity, food insecurity, health insecurity, and gender-based insecurity. This paper briefly analyses the situation of displacement in India and reflects on the insecurities faced by the people displaced due to development projects.
\end{abstract}

Keywords: Project Affected People, Displaced People, Land Acquisition

\section{Introduction}

The major problem faced by the present Indian economy is the shortage of land, which is important to fulfil the requirements of its neoliberal growth model. One of the major land issues in today's neoliberal economy of India is the land acquisition for development projects. Land in India is obtained by the state under the Doctrine

"Department of Social Work, University of Delhi, India; pinki.hrc@gmail.com 
of Eminent Domain. This Doctrine qualifies the state to gain private land for open use or for financial improvement as Right to Private Property is certainly not a crucial right in the Constitution of India. The idea of Eminent Domain is known by various names in various nations, for example, as Eminent Domain in the United States and the Philippines; as Necessary Buy in the United Kingdom, New Zealand and Ireland; Resumption/Obligatory Securing in Australia; and Seizure in South Africa and Canada. The property might be taken either for government use or by appointment to outsiders who will give it to open or urban use or for monetary improvement.

The philosophy of compulsory land acquisition has its foundation in the land law of feudal Europe and England in particular. Under the old medieval framework or feudal system all land was possessed by the Monarch, presently supplanted by the state, and his subjects held parts of it at his command. The hidden commitment was steadfastness yet the value included administrations, military or individual, for example, caring for his own prosperity by providing his needs. In time, everything came down to cash and land was levied in kind for ownership. The fundamental government still continued as before, that is, extreme possession by the state, as it supplanted the total Monarchy with the Constitutional Monarchy. Subsequently, the state even today has outright responsibility for the land and can get land from the general population whenever for the utilisation of public purpose or for the greater good of all.

After the economic reforms of 1991, land acquisition has been made easier and the state has been seen acquiring land for public sector projects as well as on behalf of the private sector. The structural adjustment programme and the ensuing conditionalities provided the rationale for liberalisation, privatisation and globalisation. By introducing the concept of special economic zones, special powers have been conferred for the economic development of those regions. The Special Economic Zones policy was announced in India in 2000 and after a gap of 5 years, the Special Economic Zones Act was passed in the Parliament in 2005. Many incentives were announced for units to be set up in SEZs such as single window clearance, exemption from duties on import/procurement of 
goods, income tax exemption for a block of 10 years, exemption from service tax, and so forth.

Be it land acquisition by private players or by the state, it has been seen by and large that the rights of the landowners or those dependent on land - whether farmers or forest dwellers are being ignored. The clauses of the existing law are easily being manipulated by accessing the loopholes therein. In the process, the most marginalised section of the society, i.e., the Dalits, the tribals, women and small-scale farmers are being worst hit. Parasuraman (1996), notes that medium-sized farms become small. Smallholders previously precariously balanced above the poverty line may fall below it and never recover, even without becoming landless. Two social and economic implications of land acquisition are displacement and resettlement and rehabilitation of those displaced. The displaced people have to deal with several insecurities in the process of their rehabilitation because they are uprooted from their base and are surrounded by a lot of inhibitions regarding their future.

Development and displacement are essentially contrasting in nature. While Myrdal has defined "development as the upward movement of the entire social system", Cernea says developmentinduced displacement has mostly caused downward "spiral of impoverishments". Displacement implies a redefinition of people's privilege and access to socio-social, monetary and natural assets. It causes genuine monetary, social and social interruption of the lives of those influenced by it and the social texture of the networks of the territory. This paper is a review article based on an extensive review of available literature and reflects on the situation of development-induced displacement in India and the insecurities faced by the displaced people.

\section{The Situation of Displacement}

\subsection{The Colonial Age}

Development-induced displacement has existed from the old occasions yet turned into a noteworthy issue with imperialism and got escalated with post-independence arranged advancement. Globalisation includes a more noteworthy assault to the sustenance 
of most ancient networks. The present issue began with imperialism whose goal was to transform South Asia into a provider of capital and crude material for the British Industrial Revolution and a market for its completed items. To accomplish this target as of now from the nineteenth century the pioneer routine opened coal mineshafts in Jharkhand, tea cultivates in Assam, coffee gardens in Karnataka and different plans somewhere else (Mankodi. 1989, pp. 140-143). Likewise, lawful changes were acquainted with make land securing at a low cost simple. It started with the Permanent Settlement 1793 and finished in the Land Acquisition Act 1894 (LAQ) (Bora, 1986, p. 46) that depends on the guideline of the State's prominent area. It has two features. Right off the bat, all biodiversity and regular assets just as the land without individual titles have a place with the State. Besides, the State alone has the privilege to characterise an open reason and deny even people of their property (Ramanathan, 1999, pp. 19-20).

But most displacements by it was process-induced i.e. resulting from loss of sustenance through technological, economic and legal changes such as laws recognising only individual ownership and obstacles put in the way of the manufacturing sector in order to support British industrial products. Dalits and tribals, most of whom got indebted, became bonded labourers or migrated as indentured labour in the plantations in the British colonies the world over. Many tribals from Chhattisgarh, Jharkhand and Orissa went in slave-like conditions to work in the tea gardens of North Bengal and Assam (Sen, 1979).

\subsection{The Post-Independence Age}

Post-Independent India has kept the reasoning on improvement pretty much unaltered and has held the former laws as well as has even fortified them to make procurement simpler. Therefore, individuals continue being displaced for the sake of national improvement that involves vast scale investment in plans like dams, ventures, streets, mines and power plants. For instance, as indicated by one estimate (Nag, 2002, p. 40), 15\% of the world's vast dams between 1947-1979 were worked in India. Today the country has over 4,000 of them. These projects brought about irreversible changes in land use and in the lives of millions of its dependants. 
Development of each citizen was the aim of objective of postindependence planning yet there are indications that a prominent focus was laid on economic growth than on its benefits reaching every citizen. The dominant development paradigm suggested the use of the natural resources for projects such as mines, dams, industries, nuclear installations and military bases. They acquired land that people inhabited and in the name of national development, displaced some and deprived others of their land and sustenance without physical relocation. But only a few have asked, "development for whom, for what and at what cost?" (Seth, 2002, pp. 221-223).

That question is pertinent on the grounds that reviews demonstrate that far from improving their way of life, the kind of development denies the uprooted or displaced individuals (DP)/Project Affected People (PAP) of their sustenance (land, residence, food and nourishment, education and so forth) and denies them the right toa life of dignity. Nothing illustrates the role of structural inequalities and power dynamics better than a development-induced displacement and resettlement (DIDR) project wherein the poor, including tribal and other ethnic minorities, living in resource-rich areas are specified and intervened upon for resource extraction from their land (Ray \& Saini, 2011).

\section{Resettlement and Impoverishment}

Displacement results in impoverishment and begins with landlessness. For instance, landlessness among the Assam DPs/PAPs grew from $15.56 \%$ before the undertaking of the project to $24.38 \%$ after it (Fernandes \& Bharali, 2006, p. 188) and in AP from $10.9 \%$ to $36.5 \%$ (Fernandes et al. 2001, pp. 112-113). In Orissa, among the mining uprooted families, $16.7 \%$ of the indigenous and $13 \%$ of the Dalit DPs became landless against $3.6 \%$ of the general castes (Pandey, 1995, p. 180). The DP/PAPs experience downward mobility in their status. Most of the rich become medium, the medium ranchers become small and negligible and small and minor ranchers become landless. Many of them own only homestead land. Likewise natural resources, for example, the number of lakes, wells, poultry, steers and animal husbandry that supplement agricultural income decrease (Bharali, 2007). 
Joblessness as a result of displacement takes two forms. The first is the lack of access to work and the second is downward occupational mobility. To begin with, the project that alienates from them the land that gives them work and provides them security resettles very few of them and gives fewer jobs. For example, out of 266,500 displaced or deprived families studied in Orissa, around 9,000 were given project jobs (Fernandes \& Asif, 1997, pp. 137-139).

Studies demonstrate that the projects have caused 50-60 million DP/PAP in post-independent India (Fernandes, 2004, p. 1192), the greatest number of dams (Baboo, 2002, p. 195). Just 25\% of the DP have been resettled somewhat, some have parsimonious remuneration and others have been disregarded (Nag, 2002, p. 42). Studies have discovered that just $35.27 \%$ in Orissa, $28.82 \%$ in Andhra Pradesh, $40.78 \%$ in Goa, 13\% in Kerala and 9\% in West Bengal got resettlement advantage (Gogoi \& Lahon, 2014). Subsequently, most of them have been impoverished and marginalised for the sake of national improvement, have been pushed into a circumstance of of insecurity and have lost their right to a life with dignity.

\section{Development Induced Displacement and Human Security}

\subsection{Human Insecurity}

Human security is the totality of the social, economic and other components. Article 21 of the Constitution speaks of the right to life. In several cases, the Supreme Court has held that it is not confined to physical existence but includes in its ambit every citizen's right to a life of dignity. It includes all necessities such as adequate nutrition, shelter, work and other facilities (Vaswani 1992, pp. 158-159). Along these lines, Article 21 guarantees the security of an individual's employment. This right is mentioned also in international covenants. For example, Article 1 of the International Covenant on Economic, Social and Cultural Rights that came into force on January 3, 1976, says that all people have a right to selfdetermination. By its virtue, they determine freely their political 
status and pursue their economic, social and cultural goals (Cheria et al, 2004, p. 143).

Practically speaking, in any case, one observes a breakdown of such arrangements through acts like development-induced displacement that denies human security to the evictees DP/PAP by distancing them from their property and employment without their consent. In most cases, they are not even informed of the alienation of their livelihood. In Assam, out of 726 DP/PAP interviewed, 241 (33.19\%) came to know about it from the officials when they came to survey the land, $71(9.9 \%)$ received the information through the radio and newspapers. A percentage heard about it from other villagers and a few heard it only at the time of their displacement. There are no signs of the officials making an effort to give people information about it. Most notifications were published in newspapers to which the local people did not have access (Fernandes \& Bharali, 2006, pp. 139-140).

The harm it causes is the initial phase in instability. It happens because the Land Acquisition Act of 1894 (LAQ) that is an enabling Act for land acquisition is based on the eminent domain of the State. Its first facet is that it recognises only individual property. All biodiversity and property without an individual title belong to the State. Its second facet is that the State alone has the right to define a public purpose and deprive even individual property owners their assets (Ramanathan, 1999, pp. 19-20). The public purpose has not been defined even 112 years after the enactment of the LAQ. Displacing them by giving limited information is intrinsic to the eminent domain and it is the first step in causing trauma and insecurity. The old law demanded only formal information through a notification in two newspapers. However, in the new law, Right to Fair Compensation and Transparency in Land Acquisition, Rehabilitation and Resettlement Act, 2013, a public hearing has been made mandatory so that people come to know about the whole process of land acquisition and can voice their concerns.

The circumstance is more regrettable with regards to Common Property Resources (CPRs) on which an extensive number of the $\mathrm{DP} / \mathrm{PAP}$ depend. Yet, the law regards them as state property and its dependants as encroachers. They do not need to be educated about their displacement since the state is viewed as their 
proprietor. Many such communities have lived on that land for more than a thousand years and have developed a symbiotic relationship with it. But many of them are not even counted among the DP/PAP. That causes immense insecurity among the CPR dependents (Bharali, 2006).

The difference in the information given by the state and the real information with respect to displaced individuals and CPR was exposed in an investigation done by Fernandes and Bharali in Assam in 2006. By official count, the state utilised around 3.9 lakh people of the land of land for improvement between years of 19472000. It influenced around 400,000 people. By official count, the state used around 3.9 lakh acres of land for development between 1947-2000. It affected some 400,000 persons. In practice, the total is a little over 14 lakh acres that caused more than 19 lakh DP/PAP. More than 10 lakh acres that are not counted are CPRs that the State considers its property and is transferred from one department to another. It considered its inhabitants as encroachers whom it did not have to count among the DP/PAP. Little wonder then that more than $50 \%$ of them are tribals who are $12.4 \%$ of the population (Fernandes \& Bharali, 2006). Once the CPRs are treated as state property those who depend on them are ignored. Thus, development-induced displacement denies the security of the DP/PAP as human beings. Similar trends have been seen in other states as well. For example, in Andhra Pradesh, 25\% of the 24,92,356 acres used for development projects between 1951-1995 (Fernandes et al 2001, p. 57) and in Orissa more than 50\% of the 20 lakh acres are CPRs.

\subsection{Economic Insecurity}

A noteworthy part of human security is economic security and development-induced displacement denies common property resources to the DP/PAP curtailing their access to or supply of natural resources on which their communities depend. They are denied their security around the CPRs by treating them just as state property and overlooking their dependents. away their source of food and income and pushing them into a situation of economic insecurity. Consequently, landlessness and joblessness increase and result in an occupational shift from cultivation to daily wages, 
domestic work and other types that deny them the security of sustenance. Impoverishment is the economic consequence of depriving people of their livelihood. Michael Cernea (2000) mentions landlessness, joblessness, homelessness, marginalisation, food insecurity, increased morbidity and mortality, loss of access to CPRs and common services and social disarticulation as impoverishment risks. The first four of them lead to economic insecurity and the rest to other forms of human insecurity.

Displacement and resettlement is basically an economic issue related to loss or significant reduction of access to basic resources on which networks depend. The reduction in the economic security which affects the displaced individuals is an outcome of a few factors and the most important of which includes the following:

1. Loss of access to recently utilised assets on which they depend (water, horticultural land, and common property assets, for example, pastures, forests, basic agrarian land, and waterways).

2. Inappropriately little compensation is given which does not assess the non-material things lost related to the displacement.

3. The negative results of progress or alteration of the past financial model.

4. Deterioration of monetary and natural conditions in the new resettled area.

5. The financial outcomes of disarticulation of bigger networks and loss of existing network, neighbourhood or family ties (Terminski, n.d.).

\subsection{Social Insecurity}

The impact of development projects is not limited to the economic field but impinges on the social and cultural aspects. Deprivation leads the DP/PAP into insecurity by uprooting their communities and entire villages thereby destroying long-established social networks. The DPs/PAPs who live in an informal society are forced to interact with another culture and society to which they cannot always adapt. This insecurity results in marginalisation or 
what Cernea calls social disarticulation. Marginalisation is both economic and social. It is a decline in the social status of the $\mathrm{DP} / \mathrm{PAP}$ but basic to it is the loss of confidence in one's own community. Social disarticulation results from the loss of social networks. It fragments and destroys communities, social organisations, kinship groups and the social order (Cernea, 2000). Without preparing the DP/PAP for the new order, they lose the security they had within the social structure of their community or clan and are forced to adjust themselves to the host population.

The DP/PAPs face food insecurity after the loss of their land and forests. They depend on the little land and forest left over which they over exploit. They begin to view it not as their sustenance but as a commercial commodity. Once deprived of their livelihood, they fall back on the same resource for survival but in the process make a transition from their traditional constructive to destructive dependence on it. While in the past most of them had treated it as a renewable resource that had come down from their ancestors and had to protect for posterity, now they use the same resource as the only source of income and overexploit it (Fernandes \& Bharali 2006, p. 177).

\subsection{Health Insecurity}

This is another area of concern. Health depends to a great extent on nutrition, clean water and air. Deprivation by development projects causes food insecurity that leads to health insecurity. For example, studies in Andhra Pradesh (Fernandes et al., 2001, p. 153), Orissa (Fernandes \& Raj, 1992, p. 152) and West Bengal (Fernandes et al., 2006, p. 213) demonstrated colossal increase in waterborne diseases after the project. Another disease whose incidence had more than doubled was asthma. In projects such as mining, people become vulnerable to many diseases due to air and water pollution in neighbouring areas.

\subsection{Gender Based Insecurity}

Studies demonstrate that women endure the results of hardship more than men do suffer and suffer the consequences of deprivation more than men do (Ganguly, 1992, p. 23). The condition of women deteriorates after displacement because she 
does not remain an economic asset anymore. She is expected to play the role of a provider of the family even after the loss of resources. Men appropriate the little money they get as compensation, spend it on drinking and leave very little for their rehabilitation. Most of the women experience greater pauperisation as they have lost their independent earning avenues and are pushed to the margins of the labour market. The status of women has been reduced from being an earning member to a dependent member as they cannot go to work now. Instead of working and earning money for the family, they sit idly the whole day now just looking after the family. If the project gives jobs, except in womenheaded families, they almost go exclusively to men considered as heads of families. If they are rehabilitated, the land is allotted to men. The women have no decision- making powers. All these increase gender-based insecurities.

\section{Human Rights Law and Development Induced- Displacement}

In 1986, the United Nation General Assembly adopted a Declaration on the Right to Development, which states that "every human person and all peoples (sic) are entitled to participate in, contribute to and enjoy economic, social, cultural and political development, in which all human rights and fundamental freedoms can be fully realised." The heart of the problem is that people displaced by development projects are generally seen as a necessary sacrifice on the road to development. However, a change in paradigm has emerged in recent years with more emphasis on human rights and social justice. These rights include:

\subsection{Right to Participation}

The affected communities must be able to participate in different levels of decision-making, from the local (project), state (programme), national and international levels. The right to participation is well grounded in the International Bill of Human Rights (for instance, ICCPR, Craftsmanship 25). More specifically, the 1991 International Labour Organisation Convention Concerning Indigenous and Tribal Peoples in Independent Countries (ILO Convention 169) stipulates (Article 7) that 
indigenous and tribal people shall participate in the formulation, implementation and evaluation of national and regional development plans that affect them.

The new Right to Fair Compensation and Transparency in Land Acquisition, Rehabilitation and Resettlement Act, 2013, has provided space for people's participation in the process of land acquisition and displacement through Social Impact Assessment (SIA) and Public Hearing. The SIA has to be carried out in consultation with the representatives of the Panchayati Raj Institutions. Reports prepared under the SIA are to be shared with these individuals in their local language along with a summary.

Public hearings shall be conducted in all Gram Sabhas where more than twenty-five per cent of the members are directly or indirectly affected by the acquisition of the land. The date and venue of the public hearing must be announced and publicised three weeks in advance through public notifications and posters in all the villages within a radius of five kilometres of the land proposed to be acquired through advertisements in local newspapers, radio, and through direct communication with the Gram Panchayat or Municipal Ward representatives as well as by uploading the information on the website of the appropriate Government (Rehabilitation and Resettlement Act, 2013).

\subsection{Right to Life and Livelihood}

When security forces take action to move people forcibly or to quell civil dissent against development projects, it may constitute a direct threat to the right to life, which is protected in the Universal Declaration of Human Rights (UDHR, Article 3) and the International Covenant on Civil and Political Rights (ICCPR, Article 6). The right to livelihood is threatened by the loss of home and the means to make a living - whether farming, fishing, hunting, trading or the like - when people are displaced from habitual residences and traditional homelands. The right to own property and not to be arbitrarily deprived of this property, as well as the right to work, is spelt out in the UDHR (Articles 17 and 23, respectively) as well as in Article 6 of the International Covenant on Economic, Social and Cultural Rights (ICESCR). Article 11 of the ICESCR, moreover, provides for "the right of everyone to an 
adequate standard of living for himself and his family, including adequate food, clothing and housing, and to the continuous improvement of living conditions".

\subsection{Rights of Vulnerable Groups}

Development projects may make powerlessness through impoverishment. They significantly influence groups that are defenceless against such move, especially indigenous people and women. Human rights of vulnerable groups are protected generically in the International Bill of Human Rights. The ILO Convention 169 spells out protections for indigenous groups. The principle of non-discrimination is not only codified in the UDHR (Article 2), the ICCPR (Article 2) and the ICESCR (Article 2) but also in the 1979 Convention on the Elimination of All Forms of Discrimination against Women (CEDAW).

\subsection{Right to Remedy}

The right to remedy is asserted in the UDHR (Article 8) and in the ICCPR (Article 2). As noted in a report to the World Commission on Dams, "frequently, because of the idea of the development movement, the undertaking influenced communities to come to think about moves that have been made without their insight or assent. In this manner, they need a speedy and effectual remedy that can end on-going infringement and anticipate future ones. The privilege to remedy is along these lines pivotal to all development projects" (Internal Displacement, n.d.). http://www.internaldisplacement.org/. Training on the protection of IDPs.

\section{Conclusion}

The impact of displacement is not only limited to the economic aspect of the land oustees. It goes beyond that affecting their social and cultural integration and also up to the limit that their overall health is impacted due to changes happening in income pattern, food habits and unavailability of various services. This leads to them facing economic insecurity, social insecurity and health insecurity. In all the hue and cry about development, the people who are displaced or affected by the project are left behind to fend off themselves. 
But as a paradigm shift in recent years, we are seeing that the people affected by displacement are being given some space to stage their voices for their rights. The new $R \& R$ law provides for community participation in the whole process of resettlement and rehabilitation. People are able to voice their opinions through processes like a public hearing. The nation is now making it very clear that development projects should affect less and fewer people. Inclusive education is the need of the hour for PAPs. It became a paradigm shift for India's developmental programme from only development to becoming humanitarian development projects. It is very important to keep in mind the rights of the displaced people while aiming for higher economic development because when we claim to be a welfare state, we have to vouch for the development and growth of every section of the society.

\section{References}

Baboo, B. (2002). Dams, displacement and violation of human rights: The case of Hirakud dam in Orissa. In P. M. Katare and B.C. Barik (eds.), Development, deprivation and human rights violation, pp. 195-209. Jaipur: Rawat Publications.

Bharali, G. (2006). Development-Induced Displacement and Human Security in Assam. Paper presented at the Seminar on Human Security, Department of Political Science, Gauhati University, November 17-18, 2006.

Bharali, G. (2007). Development-induced displacement: A history of transition to impoverishment and environmental degradation. Paper presented at the Seminar on Ecology, Department of History, Dibrugarh University, March 27-28.

Bora, A. K. (1986). Pattern of land utilization in Assam. Delhi: Manas Publications.

Cernea, M. (1999). Why economic analysis is essential to resettlement: A sociologists view. In M. Cernea (ed.), The economics of involuntary resettlement: Questions and challenges. Washington, DC: World Bank.

Cernea, M. (2000). Risks, Safeguards and Reconstruction: A Model for Population Displacement and Resettlement. Economic and Political Weekly, 35(41), 3659-3678.

Cernea, M. (2006). Development-induced and conflict-induced IDPs: Bridging the research divide. Forced Migration Review, Special Issue, 25-27. 
Cheria, A.,Sriprabha, P. \& Edwin. (Eds.). (2004). A human rights approach to development. Bangalore: Books for Change.

Fernandes, W. \& Mohammed, A. (1997). Development induced displacement and rehabilitation in Orissa 1951-1995: A database on its extent and nature. New Delhi: Indian Social Institute.

Fernandes, W. \& Bharali, G. (2006). Development induced displacement in Assam 1947-2000: A quantitative and qualitative study of its extent and nature. Guwahati: North Eastern Social Research Centre.

Fernandes, W. \& Bharali, G. (2011). Uprooted for whose benefit? Development induced displacement in Assam 1947-2000. Guwahati: North Eastern Social Research Center.

Ganguly T, E. \& Singh, M. (1995). Dams and displaced in India. In Hari Mohan Mathur and Michael Cernea (Ed.), Development displacement and resettlement: Focus on Asian experiences. New Delhi: Vikas Publishing House Pvt. Ltd.

Gogoi, M. R. \& Lahon, T. (2014). Paradigm Shift: The Situation of Development Induced Displacement in India. Asian Journal of Social Sciences \& Humanities, 3(1).

Mankodi, K. (1989). Displacement and relocation: Problems and prospects. In W. Fernandes, \& E. G.Thukral. (eds.), Development, displacement and rehabilitation: Issues for a national debate, pp. 135-163. New Delhi: Indian Social Institute.

Ministry of Rural Development. (2013). The Right to Fair Compensation and Transparency in Land Acquisition, Rehabilitation and Resettlement Act.

Nag, S. (2002). Whose nation is it anyway: Nation building and displacement in Indian subcontinent. In C. J. Thomas (ed.), Dimension of displaced people in North East India, pp. 26-50. New Delhi: Regency Publication

Pandey, B. (1995). Impoverishing effects of coal mining projects: A case study of five villages in Orissa. In H. M. Mathur\& D. Marsden (eds.), Development projects and impoverishment risks: Resettling project affected people in India. (pp. 174-192). Delhi: Oxford University Press.

Parasuraman, S. (1996). Development Projects, Displacement and Outcomes for Displaced Two Case Studies. Economic and Political Weekly, 31(24), 1529-1532.

Ramanathan, U. (1999). Public purpose: Points for discussion. In W. Fernandes (ed.), The Land Acquisition (Amendment) Bill 1998: For liberalisation or for the poor?, pp. 19-24. New Delhi: Indian Social Institute

Ray, S. \& Saini, S. (2011). Development and Displacement: The Case of an Opencast Coal Mining Project in Orissa. Sociological Bulletin, 60(1), 4564. 
Rehabilitation and Resettlement Act (2013). Right to Fair compensation and Transparency in Land Acquisition. https://dolr.gov.in/ sites/ default/files/Right\%20to\%20Fair\%20Compensation\%20and\%20Trans parency $\% 20$ in $\% 20$ Land $\% 20$ Acquisition $\% 2$ C $\%$ 20Rehabilitation\%20and \%20Resettlement \%20Act \%2C\%202013.pdf

Sen, S. (1979). Agrarian relations in India 1793-1947. New Delhi: People's Publishing House.

Seth, S. (2002). Beyond compensation, resettlement and rehabilitation: Problems and perceptions and methodology. In P.M. Katare \& B.C. Barik (eds.), Development, deprivation and human rights violation. Jaipur: Rawat Publications, 221-239.

Terminski, B. (n.d.). Mining-induced displacement and resettlement: Social problem and human rights issue (a global perspective).

Thompson, C. M. (n.d.) Land Acquisition - Philosophy, Process and Procedure.

Universal Declaration of Human Rights. (1948). United Nations.

Vaswani, K. (1992). Rehabilitation laws and policies: A Critical Look. In Thukral (ed.), Big dams, displaced people: Rivers of sorrow, rivers of change. New Delhi: Sage publication. 